\title{
An Atom-probe Tomography Study of the Stability of Oxide-dispersion Strengthening Particles in 14YWT exposed to Neutron Irradiation
}

\author{
Karen Kruska $^{1 *}$, Danny J Edwards ${ }^{1}$, Jing Wang ${ }^{1}$, Takuya Yamamoto ${ }^{2}$, Charles H Henager ${ }^{1}$ \\ Richard J Kurtz ${ }^{1}$, G Robert Odette ${ }^{2}$ \\ 1. Energy and Environmental Directorate, Pacific Northwest National Laboratory, Richland, WA, \\ USA \\ 2. Department of Chemical Engineering, University of California-Santa Barbara, Santa Barbara, \\ CA, USA \\ * Corresponding author: karen.kruska@pnnl.gov
}

One of the principle remaining challenges in realizing fusion power is to develop a suitable first wall blanket material that can contain the heat and high-energy neutrons produced in the fusion reaction and allows sustained power extraction at high temperature [1]. Oxide-dispersion strengthened (ODS) alloys are among the candidates for a first wall blanket material in fusion reactors due to their exceptional high temperature performance and potential resistance to irradiation damage. Nanoscale oxide particles dispersed in the matrix of these alloys not only enhance their strength, but also act as traps for He that is generated throughout the material. Without such a capturing mechanism to disperse the He, He build-up in bubbles could promote void swelling that is detrimental to the material performance in plasma facing components. In this study, we explore the long-term stability of ODS particles as well as the formation of a Cr-rich $\alpha^{\prime}$ phase in 14YWT under extreme conditions.

14YWT is an ODS alloy with a fine dispersion of 5-10 $\mathrm{nm}$ yttrium-titanium-oxide particles. One sample was characterized in the as-received condition and a second one was neutron irradiated in HFIR at ORNL to a dose of $21.2 \mathrm{dpa}$ at $500^{\circ} \mathrm{C}$ in the JP-27 experiment $[2,3]$. Previous studies have shown atom-probe tomography (APT) to be particularly suited to analyze ODS particle size, density and composition [4-6]. APT specimen preparation was carried out in a FEI Quanta dualbeam FIB using a standard lift-out method. APT analysis was conducted using a laser-pulsed Cameca LEAP $4000 \mathrm{HR}$ at temperature of $40 \mathrm{~K}$, a pulse frequency of $200 \mathrm{kHz}$ and a pulse energy of $60 \mathrm{pJ}$ with a laser wave length of $355 \mathrm{~nm}$. A novel cluster search algorithm developed at PNNL (OPTICS) [7] was used to quantitatively evaluate ODS and $\alpha$ ' phase particles.

As illustrated in Figure 1, APT measurements revealed that there is virtually no difference in the ODS particle size distribution before and after irradiation. However, precipitation of a $\mathrm{Cr}$-rich (> 70 at.\%) $\alpha$ ' phase was observed throughout the irradiated specimen. Furthermore, as indicated in Figure 2, some $\mathrm{Cr}$ segregation to the ODS precipitates was observed. A slight enrichment in Mn and Si was also observed in some cases. These results suggest that ODS precipitates are stable at the extreme testing conditions, however, $\alpha^{\prime}$ phase precipitation will take place at $500{ }^{\circ} \mathrm{C}$ irradiation temperature [8].

References:

[1] M. Abdou et al., Fusion Engineering and Design 100 (2015) 2-43.

[2] T. Yamamoto et al., J Nucl Mater 367-370 (2007) 399-410. 
[3] R.J. Kurtz et al., J Nucl Mater 367-370 (2007) 417-422.

[4] C.A. Williams et al., J Nucl Mater 400 (2010) 37-45.

[5] M.K. Miller et al., Intermetallics 13 (2005) 387-392.

[6] P. Hosemann et al., J Nucl Mater 417 (2011) 274-278.

[7] J. Wang et al., Microsc Microanal, In press (2019).

[8] Acknowledgement: The work was performed at Pacific Northwest National Laboratory (PNNL), which is operated by Battelle for the United States Department of Energy (DOE) under Contract DE-AC06-76RL0-1830. This research is funded by the DOE Office of Fusion Energy Sciences under contract DE-AC05-76RL01830. A portion of this work was performed using EMSL, a national scientific user facility sponsored by DOE's Office of Biological and Environmental Research located at PNNL.
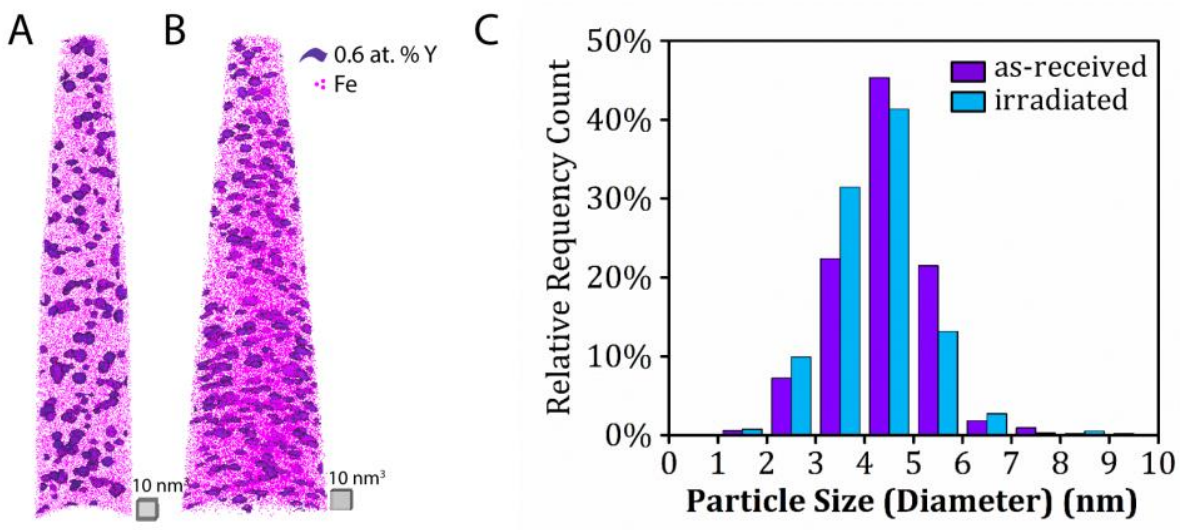

Figure 1. Ion map showing the distribution of ODS particles in 14YWT a) before irradiation and b) after irradiation. A histogram comparing the size distribution before and after irradiation is presented in c).

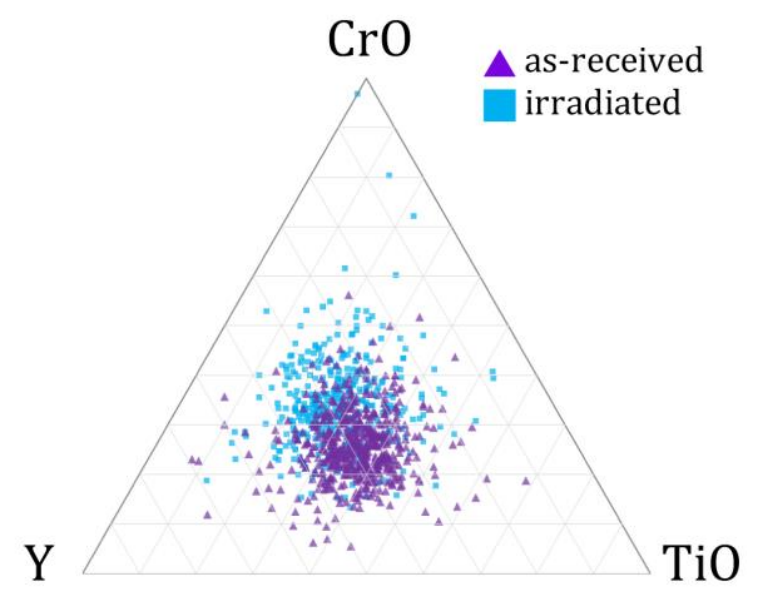

Figure 2. Ratio of the three ions, $\mathrm{Y}, \mathrm{CrO}$ and $\mathrm{TiO}$, as measured with APT in each particle. Note that these ratios are not equivalent with composition. 